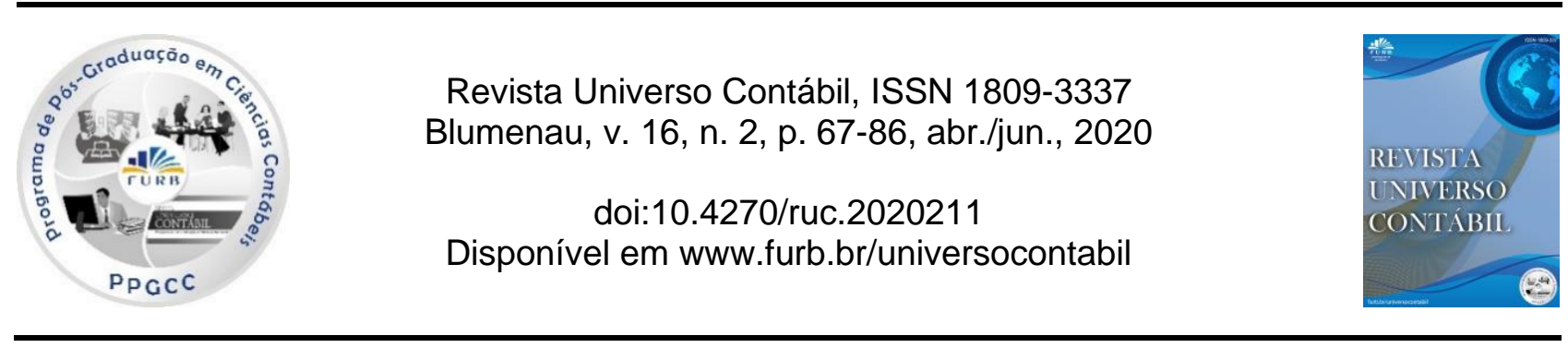

\title{
RELEVÂNCIA DA NATUREZA DOS ATIVOS INTANGÍVEIS DAS COMPANHIAS ABERTAS PARA O MERCADO ACIONÁRIO BRASILEIRO
}
RELEVANCE OF THE NATURE OF INTANGIBLE ASSETS OF OPEN COMPANIES FOR THE BRAZILIAN STOCK MARKET

\section{RELEVANCIA DE LA NATURALEZA DE LOS ACTIVOS INTANGIBLES DE LAS EMPRESAS ABIERTAS PARA EL MERCADO DE ACCIONES DE BRASILEÑO}

Recebido em: 09-05-2020

Avaliado em: 28-09-2020

Reformulado em: 14-10-2020

Aceito para publicação em: 14-12-2020

Publicado em: 26-04-2021

Editor Responsável: Roberto Carlos Klann

\author{
Juliane Pacheco ${ }^{1}$ \\ Suliani Rover ${ }^{2}$
}

\section{RESUMO}

O objetivo desta pesquisa é verificar a relevância da natureza dos ativos intangíveis das companhias de capital aberto brasileiras para o mercado acionário. Para isso, a amostra abrange as empresas não financeiras que negociam suas ações na bolsa de valores Brasil, Bolsa, Balcão (B3). O período de análise foi de 2010 a 2017, compreendendo o intervalo em vigor do CPC 04 - Ativo Intangível R1 (2010). A amostra contou com 301 empresas analisadas, abrangendo 2.184 observações. Para verificar a relevância dos ativos intangíveis, foram formuladas duas hipóteses e três equações com base no modelo de Ohlson (1995), com adaptações de Collins, Maydew e Weiss (1997). Os resultados apontaram que o ativo intangível aumentou ao longo dos anos, haja vista que passou de 348,8 bilhões de reais para 624,6 bilhões de reais. Quanto à natureza do intangível, o goodwill, as concessões e os intangíveis em serviço foram os itens mais representativos em todos os anos analisados. Nas regressões, foi observado que o intangível demonstrou relevância para o valor de mercado, apesar de ter um poder incremental baixo. Além disso, dez das 14 naturezas do intangível se mostraram relevantes. Conclui-se que os intangíveis, de modo geral, são relevantes para o mercado acionário, contribuindo com o valor de mercado.

Palavras-chave: Value Relevance. Ativo Intangível. Natureza do Intangível.

\footnotetext{
${ }^{1}$ Doutoranda em Ciências Contábeis pela Universidade Federal de Santa Catarina (UFSC); E-mail: pac.juliane@gmail.com

${ }^{2}$ Doutora em Controladoria e Contabilidade pela Universidade de São Paulo (USP); Professora do Departamento de Ciências Contábeis e do Programa de Pós-Graduação em Contabilidade da Universidade Federal de Santa Catarina (UFSC); E-mail: sulianirover@gmail.com
} 


\begin{abstract}
This research aims to verify the relevance of the nature of intangible assets of Brazilian listed companies to the capital market. The sample covers non-financial companies that trade their stocks on Brasil, Bolsa, Balcão (B3). The period was from 2010 to 2017, comprising the effective interval of CPC 04 - Intangible Assets R1 (2010). The sample had 301 companies analyzed, covering 2,184 observations. In order to verify the relevance of intangible assets, two hypotheses and three equations based on the Ohlson model (1995) with adaptations by Collins, Maydew, and Weiss (1997) were formulated. The results showed that intangible assets increased over the years, from 348.8 billion reais to 624.6 billion reais. The nature of the intangible, goodwill, concessions, and intangibles in service were the most representative items in all the analyzed years. In the regressions, it was observed that the intangible had shown relevance to the market value, despite having a low incremental power; furthermore, ten of the 14 natures of the intangible were relevant. It is concluded that intangibles, in general, are relevant to the stock market, contributing to the market value.
\end{abstract}

Keywords: Value Relevance; Intangible Asset; Nature of the Intangible.

\title{
RESUMEN
}

El propósito de esta investigación es verificar la relevancia de la naturaleza de los activos intangibles de las empresas brasileñas que cotizan en bolsa para el mercado de valores. Para esto, la muestra incluye compañías no financieras que negocian sus acciones en la bolsa de valores de Brasil. Bolsa. Balcão (B3). El período fue de 2010 a 2017, comprendiendo el rango efectivo de CPC 04 - Activos intangibles R1 (2010). La muestra incluyó 301 empresas analizadas, que comprenden 2.184 observaciones. Para verificar la relevancia de los activos intangibles, se formularon dos hipótesis y tres ecuaciones basadas en el modelo de Ohlson (1995). Los resultados mostraron que los activos intangibles aumentaron con los años, ya que aumentó de 348.8 mil millones de reales a 624.6 mil millones de reales. En cuanto a la naturaleza de los activos intangibles, la plusvalía, las concesiones y los intangibles en servicio fueron los elementos más significativos en todos los años analizados. En las regresiones, se observó que los activos intangibles eran relevantes para el valor de mercado, a pesar de tener un bajo poder incremental; Además, diez de las 14 naturalezas de lo intangible eran relevantes. Se concluye que los intangibles, en general, son relevantes para el mercado de valores, contribuyendo al valor de mercado.

Palabras-clave: Relevancia de Valor; Activo Intangible; Naturaleza de lo Intangible.

\section{INTRODUÇÃO}

Alguns itens relacionados ao desenvolvimento e fabricação de produtos, ou à criação e manutenção da demanda por eles, são advindos dos ativos intangíveis das empresas, como patentes e marcas, respectivamente (Mansuri, 2016). A inovação dos produtos para mantê-los ou incluí-los no mercado está atrelada aos esforços com pesquisa, conhecimentos, necessidades do mercado, além de avanços tecnológicos (Sorin-George \& Catalin, 2017). O impacto dos itens classificados como intangíveis pode ser notado no Relatório sobre a Propriedade Intelectual Mundial, emitido pela Organização das Nações Unidas (ONU), que revelou que um terço do valor dos produtos industrializados vendidos no mundo é referente ao capital intangível. Em 2014, o capital intelectual das empresas - como marcas, tecnologia e reputação - movimentou cerca de 5,9 trilhões de dólares (ONU, 2017), ressaltando o poder incremental do intangível nos produtos e serviços.

Empresas como Apple e Google possuem altos índices de inovação (Sorin-George \& Catalin, 2017). Juntamente com a Amazon e o Facebook, estão entre as seis empresas com maiores valores de mercado do mundo (Santos, 2018a). Ressalta-se que o uso dos seus intangíveis (marcas, pesquisa e desenvolvimento - P\&D, clientes, dentre outros) acaba criando valor no mercado acionário, visto que 
as marcas das quatro companhias juntas possuem o valor aproximado de 594 bilhões de dólares, representando 25,5\% das 100 marcas mais valiosas do mundo em 2019 (Badenhausen, 2019).

Na visão do Financial Accounting Standard Board (FASB), o usuário da informação, seja ele investidor, credor ou outro, toma como base para sua decisão as informações que a contabilidade fornece, as quais devem ser úteis. Ou seja, as demonstrações financeiras devem refletir qualquer evento que seja suscetível de afetar a atual ou futura situação financeira da empresa (Abubakar \& Abubakar, 2015).

Para Kimouche e Rouabhi (2016), as informações contábeis são relevantes quando refletem as informações utilizadas pelos investidores para determinação do valor da empresa. As pesquisas de relevância podem explicar o valor de mercado por meio de estudos de associação entre os valores contábeis e os valores de mercado durante determinado período, a fim de medir o poder explicativo.

O Pronunciamento Técnico do Comitê de Pronunciamentos Contábeis (CPC) 04 - Ativo Intangível (R1, 2010), correlato às Normas Internacionais de Contabilidade - International Accounting Standards (IAS) 38, define ativo intangível como um ativo não monetário identificável que não possui substância física. Os critérios para reconhecimento de um ativo intangível são estabelecidos pelo CPC 04 R1 (2010), o qual informa que serão reconhecidos se for provável a geração de benefícios econômicos futuros esperados, em favor da entidade, e os custos puderem ser mensurados com confiabilidade. O CPC 04 R1 (2010) destaca ainda que, quando o ativo intangível é gerado internamente, deve obedecer aos aspectos de reconhecimento em fase de desenvolvimento, para que os gastos sejam registrados. Contudo, as entidades estão proibidas de reconhecer ágio por expectativa de rentabilidade futura gerado internamente, visto a dificuldade de identificar se gerará benefícios econômicos futuros e determinar com confiabilidade o seu custo. Já quando adquirida, essa rentabilidade futura poderá ser registrada.

Em virtude disso, as demonstrações contábeis possuem diferenças entre o valor de mercado e o valor contábil. Miguel (2011) destaca que isso pode ser resultado de uma marca consolidada, carteira de clientes sólida ou tecnologias desenvolvidas que são inovadoras. Porém, por critérios contábeis, não estão registradas e/ou evidenciadas no Balanço Patrimonial. Já Chauvin e Hirschey (1994) elencam reputação comercial, relação com clientes e posição única no mercado. A reputação acaba englobando as notícias sociais e políticas, haja vista que são informações que influenciam a imagem que a companhia transmite aos seus clientes. Ademais, Chauvin e Hirschey (1994) inferem que a prática contábil subestima o valor dos intangíveis, dado os itens que não podem ser reconhecidos, todavia, são considerados no cálculo do valor de mercado da empresa. Portanto, um dos fatores desta diferença entre o valor de mercado e o valor patrimonial pode ser relacionado a itens identificáveis, sem substância física, de difícil mensuração, os intangíveis.

Com a vinda das International Financial Reporting Standards (IFRS), alguns itens intangíveis foram limitados, como, por exemplo, o registro da marca gerada internamente, por não ser mensurada com confiabilidade. Os gastos com pesquisa e desenvolvimento receberam critérios de reconhecimento, em que apenas a fase de desenvolvimento passou a ser contabilizada, desde que cumpridos todos os critérios de reconhecimento. O advento das normas contábeis internacionais, apesar das restrições apontadas anteriormente, visa aproximar o valor de mercado com o valor patrimonial.

Portanto, a referida pesquisa questiona: Qual a relevância da natureza dos ativos intangíveis para o valor de mercado das empresas brasileiras? O objetivo desta pesquisa é verificar a relevância da natureza dos ativos intangíveis das companhias de capital aberto brasileiras para o mercado acionário. Para tanto, foram elaborados os seguintes objetivos específicos: (i) indicar qual a natureza dos ativos intangíveis reconhecidos no Balanço Patrimonial das companhias de capital aberto listadas na bolsa de valores brasileira; e (ii) verificar qual a relação entre a natureza do ativo intangível e o valor de mercado nas companhias de capital aberto brasileiras.

$\mathrm{Na}$ literatura, os estudos de Herculano e Piccoli (2016), Ji e Lu (2014) e Oliveira, Rodrigues e Craig (2010) verificaram o value relevance do valor do intangível antes e após a adesão às normas 
contábeis internacionais. Ghahramanizady e Behname (2013), Kimouche e Rouabhi (2016), Silva, Souza e Klann (2017) e Pacheco, Rover e Vicente (2018) analisaram a influência dos ativos intangíveis na relevância da informação contábil. Vasconcelos, Forte e Basso (2019) investigaram o impacto dos ativos intangíveis em empresas de capital aberto. Esses autores encontraram que o intangível é relevante para o mercado acionário. Porém, focaram apenas no goodwill, ou na adesão das normas contábeis internacionais, ou em setor específico. Não estudaram como os valores registrados ou adquiridos impactam no valor de mercado desde a publicação do CPC 04 R1 (2010). Considerando a inclusão da nova conta, em 2005, as empresas puderam distinguir seus bens tangíveis dos intangíveis, podendo destacar itens que se consolidaram no mercado, como suas marcas e patentes.

Diante do exposto, a presente pesquisa visa suprir a lacuna de analisar a relevância da natureza do ativo intangível, visto que alguns intangíveis estão diretamente relacionados com a atividade principal da empresa, como concessões e licenças para exploração. Além disso, analisa o impacto do ativo intangível, registrado pela empresa ou adquirido em combinação de negócios, no valor de mercado da empresa, desde a publicação do CPC 04 R1 (2010). O estudo também expande a amostra utilizada em pesquisas anteriores, analisando todas as empresas não financeiras listadas na bolsa de valores no Brasil, em um lapso temporal de oito anos (2010 a 2017), compreendendo o período vigente da publicação do CPC 04 R1 (2010).

Em relação ao valor dos intangíveis, a principal contribuição está em verificar, por meio do modelo de Ohlson (1995), se o mercado de ações está disposto a considerar o intangível como um dos itens essenciais para se calcular o valor de mercado. Além disso, como o mercado interpreta esses valores no Balanço Patrimonial, considerando-os relevantes e confiáveis, visto que quando adquiridos em combinação de negócios, são contabilizados pelo valor justo. O estudo visa ainda contribuir sobre quais as naturezas dos intangíveis são consideradas relevantes pelo mercado, visto que algumas possuem limitações no reconhecimento. Enfim, a pesquisa contribui para a literatura sobre a relevância de valor dos intangíveis, pouco explorada no contexto brasileiro, como também para o debate sobre reconhecimento do intangível, visto que explora o período de harmonização completa das normas contábeis internacionais.

\section{RELEVÂNCIA DO ATIVO INTANGÍVEL}

A Deliberação nº 488 de 2005, da Comissão de Valores Mobiliários (CVM), modificou a estrutura das demonstrações contábeis, por meio de seus artigos 54 e 55, estabelecendo que ativos que não serão consumidos ou negociados nos próximos 12 meses, ou que não sejam dinheiro ou equivalente, serão classificados como ativo não circulante, classificado em: realizável a longo prazo, investimentos, imobilizado, intangível e diferido. Em 2008, ocorreu uma nova mudança na estrutura do ativo não circulante, excluindo o ativo diferido, visto que os valores pertencentes a ele não cumpriam o requisito de ativo. Essa divisão trouxe mudanças na estrutura das demonstrações contábeis, em virtude do acréscimo do ativo intangível. O CPC 04 R1 (2010) destaca que um ativo intangível deve ser reconhecido se possuir a capacidade de gerar benefícios econômicos futuros em favor da entidade que o controla, e o custo puder ser mensurado com confiabilidade.

Exemplos de intangível são: marcas, patentes, direitos autorais e contratuais, software e desenvolvimento, conforme a Tabela 1. Os desenvolvimentos são os gastos que passaram a ser contabilizados no ativo, após preencherem os critérios de reconhecimento estabelecidos no CPC 04 R1 (2010), como a intenção e a viabilidade técnica e financeira de conclusão desse ativo; finalizar com intuito de vender ou usar; confiabilidade na mensuração dos gastos; e a forma como irá gerar benefícios econômicos futuros. Esse desenvolvimento pode incluir novas tecnologias ou melhoria de produtos e serviços, como novos produtos e serviços no mercado, indicando as intenções da empresa em inovar. 
Juliane Pacheco, Suliani Rover

Tabela 1 - Natureza dos ativos intangíveis

\begin{tabular}{|l|l|}
\hline Natureza & Conceito \\
\hline $\begin{array}{l}\text { Carteira de } \\
\text { clientes }\end{array}$ & Base na qual os clientes ativos e em potencial são cadastrados (Mantovani \& Santos, 2014). \\
\hline Concessões & $\begin{array}{l}\text { Concessão cedida à entidade privada com intuito de prestar serviços públicos ou melhorá-los por } \\
\text { um prazo específico (Zittei, Kloeppel, \& Klann, 2013). }\end{array}$ \\
\hline Direitos & $\begin{array}{l}\text { Direito concedido a terceiros para comercialização, produção ou exploração sobre recursos } \\
\text { naturais, públicos, artísticos, dentre outros (Ritta, Ensslin, \& Ronchi, 2010). }\end{array}$ \\
\hline $\begin{array}{l}\text { Fundo de } \\
\text { comércio }\end{array}$ & $\begin{array}{l}\text { Corresponde a bens materiais e imateriais reunidos a fim de produzir benefícios econômicos. } \\
\text { Entre os bens estão mercadorias, instalações, marcas, patentes, clientes, ponto do estabelecimento } \\
\text { (Bizotto, Rali, Ribeiro, \& Stancki, 2014). }\end{array}$ \\
\hline Goodwill & $\begin{array}{l}\text { "Montante de lucros futuros esperados acima da rentabilidade normal de uma empresa, mensurado } \\
\text { pela diferença entre o valor da empresa e o seu patrimônio líquido avaliado a valores de mercado" } \\
\text { (Martins, Almeida, Martins, \& Costa., 2010, p.3) }\end{array}$ \\
\hline Marcas & $\begin{array}{l}\text { Conjunto de bens, direitos e obrigações ligados ao nome ou símbolo que adiciona ou subtrai o } \\
\text { valor fornecido por um produto ou serviço (Abubakar \& Abubakar, 2015). }\end{array}$ \\
\hline Patentes & "É uma invenção que causa desenvolvimento tecnológico" (Ritta et al., 2010, p. 65). \\
\hline Desenvolvimento & $\begin{array}{l}\text { "Desenvolvimento é a aplicação dos resultados da pesquisa ou de outros conhecimentos em um } \\
\text { plano ou projeto visando à produção de materiais, dispositivos, produtos, processos, sistemas ou } \\
\text { serviços novos ou substancialmente aprimorados, antes do início da sua produção comercial ou } \\
\text { do seu uso" (CPC 04 R1, 2010, p.5-6). }\end{array}$ \\
\hline "Sistemas lógicos que processam dados de acordo com instruções programadas" (Ritta et al., \\
2010, p. 65).
\end{tabular}

Fonte: Abubakar e Abubakar (2015); Bizotto et al. (2014); CPC 04 R1 (2010); Zittei et al. (2013); Mantovani e Santos (2014); Martins et al. (2010); Ritta et al. (2010).

Ritta et al. (2010, p. 65) relatam que "esses ativos intangíveis combinados com outros fatores, tais como localização geográfica, habilidades gerenciais e aspectos comerciais propiciam vantagens na geração de resultados e um diferencial competitivo no mercado empresarial". Porém, capacidade de inovação, recursos humanos, know-how, relação com clientes e fornecedores, apesar de serem intangíveis, não podem ser registrados no Balanço Patrimonial quando gerados internamente. Isso acarreta o não acompanhamento do processo contábil na evolução das empresas da era da informação, prejudicando a criação de seu valor futuro (Abubakar \&Abubakar, 2015). Castro (2015) relata que os intangíveis, nas últimas décadas, aumentaram de forma relevante, mas a norma contábil ainda restringe o registro dos ativos intangíveis gerados internamente, exceto quando ocorre uma combinação de negócios, quando a empresa adquirente poderá registrar esses ativos. O não reconhecimento por conta dos padrões contábeis pode afetar a relevância da contabilidade (GarcíaAyuso, 2003).

Para Cassel, Hackl e Westlund (2000), os intangíveis, quando se referem às dimensões qualitativas do valor da empresa - como ativo de clientes, funcionários, capital intelectual e estrutural - estão se tornando cada vez mais importantes. Para Chauvin e Hirschey (1994), do ponto de vista contábil, apenas os ativos que contemplam os princípios aceitos são registrados, enquanto do ponto de vista econômico, o valor de mercado engloba o valor presente líquido dos fluxos de caixa futuros previstos, que são capturados pelo mercado acionário pela alta qualidade das informações, como $\mathrm{P} \& \mathrm{D}$ e marca/propaganda.

Ressalta-se que a diferença entre o valor de mercado e o valor contábil não é exclusivamente devido à existência de intangíveis não contabilizados. García-Ayuso (2003) elenca como outra possível explicação a subvalorização de ativos tangíveis e financeiros, ou ainda, que o preço das ações pode conter estimativas imparciais do valor da empresa. Silva et al. (2017) argumentam que o reconhecimento e a evidenciação de ativos intangíveis contribuem na criação de valor de mercado, influenciando agentes econômicos nos investimentos futuros. Pacheco et al. (2018) destacam que o 
nível de evidenciação dos ativos intangíveis está positivamente relacionado ao preço das ações, com $62,93 \%$, em média, de evidenciação, demonstrando que os acionistas carecem dessas informações para tomada de decisão. Segundo Fama (1970), o preço de mercado de uma ação reflete todas as informações, de forma que a ação e o valor patrimonial sejam estimados de acordo com a Teoria de Mercados Eficientes.

As informações contábeis são elaboradas para fornecer aos usuários informações sobre a empresa, porém, pelos critérios contábeis, gastos com pesquisa de novos produtos não podem ser reconhecidos por não cumprirem esses critérios. Assim, as informações complementares são fundamentais para que os usuários compreendam as atividades e os novos projetos. Por exemplo, empresas de alta tecnologia podem informar - em notas explicativas, quadro suplementares ou relatório da administração - os gastos referentes a novos projetos que foram alocados como despesa na demonstração do resultado, por conta dos critérios de reconhecimento, mas que no futuro poderão gerar retornos positivos. Aboody e Lev (1998) destacaram que a alocação em despesa de custo de desenvolvimento de softwares estava associada ao retorno subsequente das ações, indicando aos investidores informações relevantes sobre futuras capitalizações de softwares.

A avaliação de uma empresa considera tanto os valores que compõem o balanço patrimonial, bens tangíveis e intangíveis, como valores que não estão no balanço, como é o caso do nome da empresa, carteira de clientes, know-how, capital humano, dentre outros, que ao longo da existência da empresa foram criados (Santos, 2018b). Dessa forma, os intangíveis influenciam o valor econômico das empresas, dependendo inclusive do setor de atuação, do ciclo de vida do produto e da empresa, entre outros (Kayo, Kimura, Martin, \& Nakamura, 2006).

Ao abordar uma metodologia de variação de ativos intangíveis não registrados no balanço patrimonial da empresa, Vasconcelos et al. (2019) encontraram que os ativos intangíveis de empresas de capital aberto na Alemanha, na Inglaterra e em Portugal possuíam um impacto positivo no valor de mercado, de acordo com os índices de intangibilidade. Entretanto, os resultados foram prejudicados pela criação de valor para os acionistas, visto que estes se mostraram contrários ao esperado. Os autores ressaltaram ainda as dificuldades que os intangíveis geram para o mercado no momento de reconhecimento, mensuração e valorização.

Em uma fusão ou aquisição, por exemplo, a avaliação da empresa é realizada normalmente com base no método de fluxo de caixa descontado. Com isso, esses intangíveis que não estão registrados serão mensurados pelo valor justo e a adquirente poderá registrá-los como ativo. Segundo Patrocínio, Kayo e Kimura (2007), as empresas que apresentaram um nível de intangibilidade acima da média continuaram obtendo retorno anormal 16 dias após o anúncio, diferente das empresas classificadas como tangíveis. Resultado similar foi encontrado por Lev e Sougiannis (1996), em que a capitalização de $\mathrm{P} \& \mathrm{D}$ estava fortemente associada ao retorno das ações, indicando informações relevantes para os investidores.

Há uma preocupação de que a ausência desses valores nos Balanços Patrimoniais leve à deterioração da qualidade da informação contábil, visto que esse aumento de despesas acaba gerando relatórios tendenciosos, uma vez que o valor alocado na demonstração do resultado pode vir a ser um gerador de benefício econômico futuro. Ao comparar o valor de mercado com o valor contábil, podese perceber se há fatores que não foram mensurados e que, mesmo tendo essa diferença reduzida ao longo dos anos, uma parcela dela é atribuída aos ativos intangíveis (Lev, 2003). Cabe, portanto, às informações financeiras indicarem que intangíveis poderiam ser esses. Por isso, estudos que avaliam qual informação contábil é relevante ajudam os preparadores dos relatórios contábeis, pois eles não estão em contato com todos os usuários (Benston, 1967).

Os estudos de Ball e Brown (1968) e Beaver (1968) relataram que o mercado reage ao lucro divulgado, indicando que este é uma informação útil ao mercado. Ball e Brown (1968) acrescentaram que existem outras informações além do lucro que são úteis para os usuários. Por meio de uma abordagem estatística, pode-se confirmar se os ativos intangíveis são relevantes para o mercado acionário e, conforme Barth, Beaver e Landsman (2011). estende o conhecimento sobre a relevância 
de valores contábeis. Se a negociação da ação é volumosa, indica as expectativas dos investidores sobre o valor da empresa (Ghahramanizady \& Behname, 2013). Nas pesquisas sobre value relevance é estudada a relação entre o valor da empresa e suas informações. Assim, uma informação é dita como value relevant se for considerada importante para os usuários da informação.

Diversos estudos analisaram a influência do ativo intangível e se seu valor era relevante para o mercado de capitais. Dentre os estudos internacionais, pode-se citar Collins et al. (1997), Ghahramanizady e Behname (2013), Ji e Lu (2014), Kallupar e Kwan (2004) e Kimouche e Rouabhi (2016). Já no âmbito nacional, Carlos Filho, Silva Filho, Lagioia, Silva e Araújo (2013), Herculano e Piccoli (2016) e Silva et al. (2017).

Ao investigar a mudança no value relevance do lucro líquido e do patrimônio líquido entre 1953 e 1993, Collins et al. (1997) acreditavam que não seria explicado pelo aumento de ativos intangíveis. Entretanto, além do ativo intangível aumentar de 7\% para 21\% em 1993, os achados apontaram um aumento de 0,540 para 0,567 no poder explicativo. Quando analisaram separadamente a variável patrimônio líquido, o intangível incrementou o poder explicativo em 0,092 (r2 0,896), além de estar positivamente associado ao preço das ações. Esse resultado indicou que o valor contábil patrimonial tende a ser mais relevante em empresas que aumentaram seus intangíveis; o mesmo não ocorreu quando se realizou essa análise com o lucro líquido. As conclusões foram que o value relevance do lucro líquido e do patrimônio líquido não diminuiu ao longo de 40 anos. Pelo contrário, aumentou, mesmo com o incremento dos prejuízos, devido ao reconhecimento de gastos com P\&D.

O período pré e pós-adoção das IFRS foi estudado por Ji e Lu (2014) e Carlos Filho et al. (2013). O primeiro encontrou uma redução na relevância dos intangíveis na Austrália, que pode ter ocorrido em decorrência do rigor para capitalização, bem como certos intangíveis que não podiam mais ser contabilizados no Balanço Patrimonial, como por exemplo, $\mathrm{P} \& \mathrm{D}$, marcas e ágio gerado internamente. Entretanto, os intangíveis continuavam sendo relevantes e confiáveis para as empresas australianas. Carlos Filho et al. (2013) observaram um aumento no registro de intangíveis. Além disso, os investidores não distinguiam entre o tipo de intangíveis (identificado ou goodwill), concluindo que, se a empresa possuía intangíveis, suas ações eram mais elevadas.

Os estudos sobre os intangíveis e a adoção das normas internacionais indicaram relevância para o mercado acionário e um aumento no reconhecimento dos intangíveis após a implementação das IFRS (Ji \& Lu, 2014; Carlos Filho et al., 2013). Porém, esses estudos discordam quanto à sua relevância após a adoção; no contexto australiano, o intangível reduziu, enquanto, no contexto brasileiro, aumentou.

Oliveira et al. (2010) acreditam em três possíveis razões para a adoção das IFRS aumentar a relevância do valor: (i) o aprimoramento necessário das divulgações; (ii) um mercado mais justo pela orientação das contabilizações; e (iii) o gerenciamento de resultados foi dificultado. Os autores concluem, ao analisar empresas portuguesas, que os investidores consideram os intangíveis em desenvolvimento e as antecipações de compra de intangíveis identificados como fontes de benefícios econômicos futuros, tanto pelo GAAP português como pelas IFRS.

Com intuito de examinar a relevância e a confiabilidade das marcas, Kallupar e Kwan (2004) estudaram o contexto do Reino Unido, no período de 1984 a 1998. Marcas geradas internamente foram encontradas em três de 33 empresas. Nesses casos, deve haver uma descrição gerencial para a valoração, na qual constem os custos de substituição e valores realizáveis. Os resultados, analisados pelos coeficientes, foram significativos e apontaram que a marca é relevante para o mercado, de modo que o valor da marca é confiável e, mesmo se houver erro na medição, não elimina a sua relevância.

Ghahramanizady e Behname (2013) encontraram que os ativos intangíveis identificados e o goodwill estavam relacionados com o valor de mercado das empresas do Irã ( $\mathrm{r} 2$ de 77\%), indicando que os gerentes e contadores das empresas atentavam-se à quantidade de intangíveis relatados nas demonstrações contábeis, para que o valor de mercado não diminuísse. Em contrapartida, competia aos auditores distinguir se havia abuso dos gestores no reconhecimento excessivo de intangíveis com a finalidade de atrair investidores. No contexto francês, Kimouche e Rouabhi (2016) verificaram que 
o value relevance dos ativos intangíveis possuía um poder explicativo de 39,7\%, evidenciando o efeito positivo para o valor de mercado do ativo intangível e do goodwill, com o coeficiente deste último superior ao primeiro.

Ao analisar a influência do valor dos ativos intangíveis reconhecidos após adoção obrigatória de 2010 a 2012, Herculano e Piccoli (2016) encontraram uma relação positiva e significativa entre o valor da ação e o intangível, mas apenas para o identificável. Em estudo similar, Silva et al. (2017) analisaram a criação de valor dos ativos intangíveis em empresas brasileiras, no período de 2010 a 2013. Encontraram que até seis meses após a publicação das demonstrações financeiras, tanto os intangíveis identificados como o goodwill impactavam o preço das ações. O goodwill, inclusive, melhorou o poder explicativo do patrimônio líquido, visto que ele se tornou significativo no modelo de seis meses após a publicação. Os autores concluíram que a inclusão dos ativos intangíveis identificados e do goodwill na análise de value relevance da informação contábil ajudava na criação do valor de mercado, influenciando a tomada de decisão dos usuários da informação.

Ao realizar uma comparação entre o poder explicativo da contabilidade societária e da contabilidade regulatória nas empresas de energia elétrica, Cordeiro, Carmo e Ribeiro (2017) encontraram um poder explicativo maior para a contabilidade societária. O lucro líquido e o patrimônio líquido, quando coletados das demonstrações contábeis societárias, geravam informações contábeis mais relevantes para os investidores. Os autores sugerem que esse resultado pode ser devido aos diferentes critérios entre a contabilidade regulatória e societária no reconhecimento de ativos e passivos. Além disso, como as companhias registradas na bolsa de valores estão sujeitas à CVM, cujo foco é o interesse do investidor, a contabilidade societária seria mais interessante, visto que a regulatória visa atender aos objetivos do órgão regulador. Os autores concluíram que ambas eram relevantes para o mercado de capitais, levando-se em conta o alto poder explicativo dos modelos (55,6\% contra 51,2\%). O estudo de Ferreira, Carmo, Moura e Ribeiro (2017) encontrou baixo poder explicativo do ativo intangível relativo aos contratos de concessões das empresas de energia elétrica no Brasil, para explicar o comportamento das ações no período de 2010 a 2015. Uma possível explicação é que esses valores anteriormente estavam registrados no ativo imobilizado, o que induz que a nova classificação dos valores que agora compõem o ativo intangível, juntamente com o ativo financeiro, não acrescentou valor informativo.

Ao analisar o value relevance do nível de disclosure das combinações de negócios no cenário brasileiro, durante o período de 2010 a 2013, Souza e Borba (2017) encontraram uma relação positiva e significativa. Entretanto, os valores do goodwill e dos intangíveis identificados em combinações de negócios não se mostraram relevantes para o mercado, sugerindo que não eram relevantes para explicar o preço das ações. Sobre os intangíveis reconhecidos em combinações de negócios, Eloy e Souza (2018) apontaram que entre 2012 e 2014, mais da metade das contraprestações foram atribuídas ao goodwill. Em contrapartida, cinco registraram apenas intangíveis identificados, sendo as marcas e carteiras de clientes os itens mais reconhecidos.

Os estudos sobre adoção das normas contábeis internacionais e o impacto no registro dos intangíveis mostram a sua relevância para o mercado de ações, apesar de Ji e Lu (2014) indicarem um baixo poder explicativo devido às exigências para o reconhecimento. Os estudos nacionais e internacionais também indicam que o ativo intangível exerce uma influência sobre o preço das ações (Ghahramanizady \& Behname, 2013; Herculano \& Piccoli, 2016; Kimouche \& Rouabhi, 2016; Silva et al., 2017). Além disso, a natureza do intangível foi abordada com foco no goodwill e outros intangíveis (Carlos Filho et al., 2013; Ferreira et al., 2017; Kallupar \& Kwan, 2004; Kimouche \& Rouabhi, 2016; Souza \& Borba, 2017). Portanto, não foram destacados os demais tipos de intangíveis existentes, como marca, carteira de clientes, direitos e concessões, desenvolvimento, licenças, entre outros. Dessa forma, esses estudos embasam as seguintes hipóteses de pesquisa:

Hipótese 1: O valor do ativo intangível está positivamente relacionado com o valor de mercado. 
Hipótese 2: A natureza do ativo intangível está positivamente relacionada com o valor de mercado.

Os estudos abordados anteriormente indicam que os intangíveis podem ser considerados importantes para criação de valor das empresas. Em relação aos estudos anteriores, a presente pesquisa se difere pelo foco, visto que analisou o período pós-adoção das normas contábeis internacionais, iniciando pelo período de publicação do CPC 04 R1 (2010). Além disso, de forma mais ampla, analisa todas as empresas não financeiras da bolsa de valores brasileira. Ademais, não há estudos que verificam se a natureza do intangível como informação contábil é relevante para o mercado de capitais brasileiro.

\section{PROCEDIMENTOS METODOLÓGICOS}

Para verificar a influência que o ativo intangível exerce no mercado, foi analisado o período de 2010 a 2017, visto que o CPC 04 foi aprovado e divulgado no fim de 2010. Portanto, os oito anos analisados referem-se ao lapso posterior à sua entrada em vigor. A população é constituída por 324 companhias não financeiras de capital aberto listadas na Brasil, Bolsa, Balcão (B3). Dessas, fizeram parte da amostra as que apresentaram no Balanço Patrimonial o saldo da conta de ativo intangível maior que zero em pelo menos um dos anos analisados (2010 a 2017), totalizando 309 empresas. Foram excluídas oito empresas em razão do encerramento do exercício social divergir de 31 de dezembro. Portanto, a amostra final é composta por 301 empresas.

Para a análise do ativo intangível, foram utilizadas as notas explicativas com as demonstrações consolidadas publicadas no final do exercício (31 de dezembro). Caso não haja consolidação na empresa, utilizaram-se as demonstrações individuais.

Tabela 2 - Observações por ano

\begin{tabular}{lccccccccc}
\hline Ano & $\mathbf{2 0 1 0}$ & $\mathbf{2 0 1 1}$ & $\mathbf{2 0 1 2}$ & $\mathbf{2 0 1 3}$ & $\mathbf{2 0 1 4}$ & $\mathbf{2 0 1 5}$ & $\mathbf{2 0 1 6}$ & $\mathbf{2 0 1 7}$ & Total \\
\hline Amostra/observações & 301 & 301 & 301 & 301 & 301 & 301 & 301 & 301 & $\mathbf{2 . 4 0 8}$ \\
(-) Sem intangível & 12 & 10 & 8 & 6 & 6 & 5 & 5 & 4 & $\mathbf{5 6}$ \\
(-) Sem ações na bolsa de valores & 42 & 35 & 28 & 22 & 17 & 15 & 3 & - & $\mathbf{1 6 2}$ \\
(-) Encerramento exercício social & 2 & 2 & 2 & - & - & - & - & - & $\mathbf{6}$ \\
\hline Total & $\mathbf{2 4 5}$ & $\mathbf{2 5 4}$ & $\mathbf{2 6 3}$ & $\mathbf{2 7 3}$ & $\mathbf{2 7 8}$ & $\mathbf{2 8 1}$ & $\mathbf{2 9 3}$ & $\mathbf{2 9 7}$ & $\mathbf{2 . 1 8 4}$ \\
\hline
\end{tabular}

Fonte: Elaborado com base nos dados da pesquisa.

As 301 empresas que compuseram a amostra final geraram 2.408 observações, conforme descrito na Tabela 2. Das 2.408 observações foram excluídas 224, sendo 56 por não apresentarem intangível no referido ano, 162 por ainda não possuírem ações na bolsa de valores brasileira e seis observações em virtude do exercício social no referido ano divergir de 31 de dezembro, restando, assim, 2.184 observações.

Para atingir o objetivo específico de indicar a natureza dos ativos intangíveis reconhecidos no Balanço Patrimonial, foi coletada a natureza do intangível e seu valor registrado nas notas explicativas. O valor inflacionado do intangível total foi coletado no software Economatica. A Tabela 3 apresenta os grupos de natureza dos intangíveis e a composição de cada conta, na qual as 2.184 observações foram segregadas. Desse modo, o intuito do primeiro objetivo específico é identificar qual a composição do valor do intangível para as empresas da amostra. Os grupos de natureza dos intangíveis foram elaborados com base no estudo feito pela Ernst e Young em 2013, com exceção da concessão e licença, que nesta pesquisa foram segregados.

Os grupos em serviço e em curso referem-se especificamente ao segmento de energia elétrica (setor de utilidade pública), visto que algumas empresas não fizeram distinção entre os intangíveis vinculados que estão operando e os que estão em desenvolvimento. Além disso, algumas apresentaram apenas valores relativos à distribuição, administração, geração e transmissão. 
RELEVÂNCIA DA NATUREZA DOS ATIVOS INTANGÍVEIS DAS COMPANHIAS ABERTAS PARA O MERCADO ACIONÁRIO BRASILEIRO

Tabela 3 - Composição dos grupos da natureza do intangível

\begin{tabular}{|c|c|}
\hline Grupo de natureza & Composição \\
\hline Direitos e cessões & $\begin{array}{l}\text { Direitos de uso, direitos de propriedade, direitos de exploração, direitos autorais, cessão } \\
\text { de direitos, cessão comercial, dentre outros. }\end{array}$ \\
\hline Software & $\begin{array}{l}\text { Software, direitos de uso de software, licenças de software, cessão de direito de } \\
\text { softwares, computadores e software e programas de computador. }\end{array}$ \\
\hline Sistemas e implantações & Implantações de sistemas, sistemas, e desenvolvimento de websites e sistemas. \\
\hline Marcas e patentes & Marcas e/ou patentes; marcas e fórmulas; marcas, licenças e patentes. \\
\hline Concessões & Concessões, direitos de concessões, outorga de concessão e outorgas fixas. \\
\hline Desenvolvimento & $\begin{array}{l}\text { Valores com } \mathrm{P} \& \mathrm{D} \text {, projetos, desenvolvimento, em andamento, gastos/custos com } \\
\text { desenvolvimento, desenvolvido internamente que foram contabilizados no ativo } \\
\text { intangível. Não estão inseridos valores alocados como despesa do período. }\end{array}$ \\
\hline Em serviço & $\begin{array}{l}\text { Direito em uso, concessão, software, obrigações vinculadas à concessão, segregados ou } \\
\text { não em distribuição, administração, geração, transmissão. }\end{array}$ \\
\hline Em curso & $\begin{array}{l}\text { Direito em uso, concessão, software, obrigações vinculadas à concessão, segregados ou } \\
\text { não em distribuição, administração, geração, transmissão. }\end{array}$ \\
\hline Licenças & Licenças de uso, licenças regulatórias, licença de projetos, licença de operação. \\
\hline Fundo de comércio & $\begin{array}{l}\text { Valores alocados à rubrica fundo de comércio, delimitado por algumas empresas como } \\
\text { sendo ponto comercial. }\end{array}$ \\
\hline Carteira de clientes & Valores alocados à rubrica carteira de clientes. \\
\hline Goodwill & $\begin{array}{l}\text { Ágio por expectativa de rentabilidade futura, goodwill, diferença entre o valor pago e o } \\
\text { valor justo dos ativos e passivos adquiridos em combinação de negócios. }\end{array}$ \\
\hline $\begin{array}{l}\text { Intangível reconhecido em } \\
\text { combinação de negócios }\end{array}$ & $\begin{array}{l}\text { Intangíveis reconhecidos em combinações de negócios, como marca, carteira de } \\
\text { clientes, software, fundo de comércio, relacionamento com clientes, dentre outros. }\end{array}$ \\
\hline Outros & $\begin{array}{l}\text { Franquias, intangível arrendado, provisões, benfeitorias, tecnologia, acordos, } \\
\text { relacionamento e/ou contrato com clientes e fornecedores, outros. }\end{array}$ \\
\hline
\end{tabular}

Fonte: adaptado de Ernst e Young (2013).

Sobre o segundo objetivo específico, de verificar a relação entre a natureza do ativo intangível e o valor de mercado, utilizou-se o modelo de Ohlson (1995), adaptado por Collins et al. (1997), conforme a Equação 1. Para o valor de mercado considerou-se três meses após o encerramento do exercício (Kallupar \& Kwan, 2004; Ji \& Lu, 2014), visto ser o prazo para divulgação das demonstrações. Decorrido o prazo, a divulgação das demonstrações contábeis acaba incorpora no preço das ações (Shah, Liang, \& Akbar; 2013) e, consequentemente, no valor de mercado. As variáveis de controle foram patrimônio líquido e resultado líquido (Carlos Filho et al., 2013; Ferreira et al., 2017; Ghahramanizady \& Behname, 2013; Kallupar \& Kwan, 2004; Kimouche \& Rouabhi 2016; Silva et al., 2017; Souza \& Borba, 2017). Para verificar, portanto, se a natureza e o valor do intangível são relevantes para o mercado de ações, foram elaboradas as Equações 2 a 4, na qual foram acrescidas as variáveis explicativas, sendo possível verificar o poder incremental.

$$
\begin{gathered}
V M_{i, t}=\alpha_{o}+\beta_{1} P L_{i, t}+\beta_{2} R L_{i, t}+\varepsilon_{i, t} \\
V M_{i, t}=\alpha_{o}+\beta 1(P L-A I)_{i, t}+\beta_{2} R L_{i, t}+\beta_{3} A I_{i, t}+\varepsilon_{i, t} \\
V M_{i, t}=\alpha_{o}+\beta_{1}(P L-A I)_{i, t}+\beta_{2} R L_{i, t}+\beta_{3}(S E T x A I)_{i, t}+\varepsilon_{i, t} \\
V M_{i, t}=\alpha_{o}+\beta_{1}(P L-A I)_{i, t}+\beta_{2} R L_{i, t}+\beta_{3} D I R T_{i, t}+\beta_{4} S O F T_{i, t}+\beta_{5} S I S T_{i, t}+\beta_{6} M E P_{i, t}+\beta_{7} C O N C_{i, t} \\
+\beta_{8} D E S E N_{i, t}+\beta_{9} S E R V_{i, t}+\beta_{10} C U R S_{i, t}+\beta_{11} L I C_{i, t}+\beta_{12} F U N D_{i, t}+\beta_{13} C A R T_{i, t}+\beta_{14} G O O D_{i, t}+ \\
\beta_{15} \operatorname{COMB}_{i, t}+\beta_{16} O U T_{i, t}+\varepsilon_{i, t}
\end{gathered}
$$


Em que $\mathrm{VM}_{\mathrm{i}, \mathrm{t}}$ - valor de mercado da empresa $i$ três meses após o final do exercício $t ; \mathrm{PL}_{\mathrm{i}, \mathrm{t}}$ - patrimônio líquido da empresa $i$ no final do exercício $t ; \mathrm{RL}_{\mathrm{i}, \mathrm{t}}$ - resultado líquido da empresa $i$ durante o exercício do ano $t$; $\mathrm{PL}_{-} \mathrm{AI}_{\mathrm{i}, \mathrm{t}}$ - o patrimônio líquido menos o ativo intangível da empresa $i$ no período $t$; $\mathrm{AI}_{\mathrm{i}, \mathrm{t}}-$ valor do ativo intangível da empresa $i$ no período $t ; \mathrm{SET}_{\mathrm{i}, \mathrm{t}}-$ dummy do setor de atuação da empresa $i$ no período $t$; DIRT $_{\mathrm{i}, \mathrm{t}}$ - valor dos direitos e cessões da empresa $i$ no período $t$; $\mathrm{SOFT}_{\mathrm{i}, \mathrm{t}}-$ valor do software da empresa $i$ no período $t$; SIST $_{\mathrm{i}, \mathrm{t}}$ - valor dos sistemas e implantações da empresa $i$ no período $t$; $\mathrm{MEP}_{\mathrm{i}, \mathrm{t}}$ - valor das marcas e patentes da empresa $i$ no período $t$; $\mathrm{CONC}_{\mathrm{i}, \mathrm{t}}-$ valor das concessões da empresa $i$ no período $t$; DESEN $_{\mathrm{i}, \mathrm{t}}-$ valor do desenvolvimento da empresa $i$ no período $t$; $\mathrm{SERV}_{\mathrm{i}, \mathrm{t}}-$ valor do intangível em serviço da empresa $i$ no período $t$; $\mathrm{CURS}_{\mathrm{i}, \mathrm{t}}-$ valor do intangível em curso da empresa $i$ no período $t$; $\mathrm{LIC}_{\mathrm{i}, \mathrm{t}}$ - valor das licenças da empresa $i$ no período $t$; FUND $\mathrm{FU}_{\mathrm{i}, \mathrm{t}}-$ valor do fundo de comércio da empresa $i$ no período $t$; $\mathrm{CART}_{\mathrm{i}, \mathrm{t}}$ - valor da carteira de clientes da empresa $i$ no período $t$; GOOD $_{\mathrm{i}, \mathrm{t}}$ - valor do goodwill da empresa $i$ no período $t$; COMB $_{\mathrm{i}, \mathrm{t}}-$ valor do intangível identificado em combinação de negócios da empresa $i$ no período $t$; OUT $_{\mathrm{i}, \mathrm{t}}-$ valor dos outros intangíveis da empresa $i$ no período $t$.

A Equação 2 busca verificar a relevância do valor do ativo intangível, por meio do seu poder incremental (Carlos Filho et al., 2013; Ghahramanizady \& Behname, 2013; Ji \& Lu, 2014; Kimouche \& Rouabhi, 2016; Silva et al., 2017). A Equação 3 possui a intenção de verificar se o setor de atuação faz com que o intangível seja ou não relevante para o valor de mercado da empresa. Para isso, construíram-se oito dummies, uma para cada setor, tendo o setor de tecnologia da informação como base, depois multiplicou-se a dummy com o valor do intangível. Já na Equação 4 constam 14 variáveis explicativas referentes à natureza do intangível, de forma que se verifique a relevância da natureza do intangível para o valor de mercado.

Com base no modelo de regressões, estabelecido pelas Equações 2 a 4, busca-se responder as hipóteses da pesquisa, sobre o valor do ativo intangível reconhecido no Balanço Patrimonial e a natureza do intangível estarem positivamente relacionados ao valor de mercado. Por meio dos testes de LM Breusch-Pagan, Chow e Hausmman, com um p-value significante a 1\%, foi utilizado o modelo de efeitos fixos para a regressão múltipla com dados em painel não balanceado, sendo que as regressões foram realizadas no software Stata ${ }^{\circledR}$ Statistic.

A variável dependente foi coletada no software Economatica, com tolerância de 30 dias, e obteve-se o valor de mercado de 1.670 observações. Ao todo, 514 observações foram excluídas por não apresentarem o valor de mercado. Já as variáveis independentes PL e RL e o total do ativo intangível foram coletados nas Demonstrações Financeiras Padronizadas, disponíveis no site da B3. Para a Equação 4, a coleta da variável natureza do intangível ocorreu por meio das notas explicativas. Entretanto, houve empresas que não evidenciaram nota explicativa relacionada ao intangível, totalizando 1.490 observações. Além disso, quando a empresa não possuía a natureza, por exemplo, software, colocou-se valor zero, analisando-se, assim, a maneira como os intangíveis influenciam o valor de mercado. Para fins de padronização, todas as variáveis foram divididas pelo número de ações.

Devido ao PL negativo, foram removidas 152 observações e, posteriormente, foi realizado o teste de Hadi (1992) para detectar outliers na amostra. Com isso, foram excluídas 262 observações, de modo que a Equação 1 possui 1.256 observações. Para as Equações 2 e 3, além das exclusões anteriores, foram excluídas mais 190 observações em decorrência do PL-AI negativo, totalizando 1.066 observações. Para a Equação 4, que partiu de 1.490 observações, foram excluídas 106 devido ao PL negativo, 247 por meio do teste de Hadi (1992) e 191 decorrentes do PL-AI negativo, restando, assim, 946 observações. A fim de testar a correlação entre as variáveis, foi utilizado o comando "pwcorr" no software Stata® Statistic, encontrando-se correlação superior a 0,70 entre as variáveis em serviço e em curso, às demais variáveis explicativas não houve correlação. A normalidade dos resíduos foi testada pelo teste Jarque Bera e apresentou p-value superior a 5\%, indicando sua normalidade. Por fim, foi feito o teste Reset de Ramsey (1969), o qual indicou a inexistência de problemas na especificação do modelo, significativo a $1 \%$. As regressões foram realizadas utilizando o comando robusto. 


\section{ANÁLISE DE RESULTADOS}

Em 2010, o CPC 04 R1 (2010) foi publicado e passou a entrar em vigor, de forma que o lapso temporal do presente estudo se inicia neste ano. No primeiro ano do CPC 04 R1 (2010) foi possível encontrar valores registrados no intangível em 245 de 324 empresas não financeiras da bolsa de valores brasileira. Em 2017, o número de empresas não financeiras com intangível registrado chegou a 297.

Em 2010, o valor absoluto dos intangíveis era de 348,8 bilhões de reais, sendo que a soma do ativo total dessas 245 empresas era de 2.126 bilhões de reais, representando $16,4 \%$ do total de ativos, percentual que se manteve constante entre o período analisado (entre $15,1 \%$ e $16,8 \%$ ). Considerando o valor corrigido pela inflação, de 2010 a 2017, o valor do intangível aumentou 18,71\%. Apenas em 2016 houve redução do intangível, cerca de cinco por cento, porém, em 2017 voltou a crescer.

A Tabela 4 demonstra o valor absoluto por natureza dos intangíveis, conforme notas explicativas. Os grupos de concessões, goodwill e em serviço lideraram a representatividade do intangível, juntos representam mais de $60 \%$ em todos os anos. Em contrapartida, os grupos carteira de clientes, fundo de comércio e licença são os menos representativos. Ressalta-se que o fundo de comércio faz referência a um ponto comercial adquirido, alguns sem existência de desvalorização ou amortização.

Em 2014, pode-se observar que o goodwill (30,33\%) passou a ser o grupo com maior expressividade, seguido do grupo de concessões $(27,13 \%)$, que até então era o grupo mais expressivo. Já em 2015, o intangível teve um aumento de cerca de 100 bilhões, com um aumento de cerca de 30 bilhões nas concessões, em serviço e goodwill. Mesmo assim, o cenário de 2015 permanece inalterado: o goodwill foi o mais expressivo, seguido das concessões. A carteira de clientes continua sendo o item menos expressivo (0,23\%). Em 2016, pode-se observar que o goodwill e as concessões quase se igualaram em termos percentuais. O que se destaca em 2016 é o grupo licença, que desde 2011 não possuía mais de sete bilhões de reais (1,78\%), mas de 2015 para 2016 cresceu 1,22 ponto percentual. Porém, apesar de aumentar em 2017, não há um único grupo a que possa ser atribuído esse aumento, visto que os aumentos e reduções nas naturezas de 2016 para 2017 foram proporcionais, de modo que o percentual de representatividade não se alterou.

Os intangíveis gerados internamente, que não podem ser reconhecidos por falta de confiabilidade na mensuração, acabam sendo registrados pelo seu valor justo, desde que possam ser identificados, quando ocorre uma combinação de negócios. Ao longo dos anos, esses intangíveis identificados aumentaram, porém, em valores absolutos, o intangível não identificado reconhecido (goodwill) obteve um aumento superior, de 80,2 bilhões de reais para 137,2 bilhões de reais, contra 9,5 para 37,9 bilhões de reais, corroborando os achados de Eloy e Souza (2018), de que a maior parte da contraprestação é alocada ao goodwill.

$\mathrm{O}$ aumento, tanto do goodwill como dos intangíveis reconhecidos, pode ser destacado pelos valores envolvidos na contraprestação das combinações de negócios; por exemplo, a Telefônica Brasil S.A., em 2011 e 2015, comprou, respectivamente, a Vivo e a GVT, registrando 9,2 e 12,8 bilhões de reais de goodwill e 20 bilhões de intangíveis identificados.

Outro grupo que pode ter seus valores atrelados ao CPC 04 R1 (2010) é o grupo desenvolvimento. Em 2012, apesar de ter um incremento de 0,34 pontos percentuais na participação dos intangíveis total, teve um aumento de cerca de 1,7 bilhão de reais. Isso pode ser um indicativo de que as empresas estejam atendendo os critérios do CPC 04 R1 (2010) para registrar os gastos com pesquisa no balanço, ao invés de alocá-los como despesa. Em 2013, pôde-se notar que se obteve aumento considerável, de 1,67\% em 2012, passou para 2,17\% dos intangíveis em 2013. Em 2017, obteve seu maior valor, com 15,3 bilhões de reais. Todavia, sua maior representatividade foi em 2014, com 2,54\%. Ressalta-se que dentre os anos analisados foram encontrados 605 gastos com pesquisa, sendo que 357 referem-se ao setor de utilidade pública, no qual há a obrigatoriedade de destinar $1 \%$ da receita líquida para este fim. 
Juliane Pacheco, Suliani Rover

Tabela 4 - Natureza do intangível (valor em milhares de reais)

\begin{tabular}{|c|c|c|c|c|c|c|c|c|}
\hline \multirow{2}{*}{$\begin{array}{l}\text { Ano } \\
\text { Grupo de natureza }\end{array}$} & \multicolumn{2}{|l|}{2010} & \multicolumn{2}{|l|}{2011} & \multicolumn{2}{|l|}{2012} & \multicolumn{2}{|l|}{2013} \\
\hline & Valor & $(\%)$ & Valor & $(\%)$ & Valor & $(\%)$ & Valor & $(\%)$ \\
\hline Direitos e cessões & 15.739 .670 & 4,52 & 17.216 .937 & 4,19 & 17.794 .760 & 4,11 & 15.155 .525 & 3,28 \\
\hline Softwares & 4.535 .145 & 1,30 & 8.602 .269 & 2,09 & 9.395 .761 & 2,17 & 10.741 .199 & 2,32 \\
\hline Sistemas e & 1.894 .598 & 0,54 & 2.293 .444 & 0,56 & 3.876 .627 & 0,90 & 2.360 .583 & 0,51 \\
\hline Marc & 3.591 .105 & 1,03 & 4.238.312 & 1,03 & 4.353 .257 & 1,01 & 7.370 .945 & 1,59 \\
\hline Conc & 136.779 .789 & 39,26 & 140.723 .434 & 34,24 & 164.303 .062 & 37,99 & 150.577 .856 & 32,58 \\
\hline olvimento & 5.552 .221 & 1,59 & 5.483 .564 & 1,33 & 7.225 .090 & 1,67 & 10.029 .651 & 2,17 \\
\hline Em S & 49.622 .390 & 14,24 & 54.495 .760 & 13,26 & 41.450 .502 & 9,58 & 43.707 .540 & 9,46 \\
\hline Em & 8.516 .172 & 2,44 & 12.697 .770 & 3,09 & 10.801 .160 & 2,50 & 13.005 .176 & 2,81 \\
\hline Lice & 2.741 .110 & 0,79 & 1.437 .622 & 0,35 & 7.496 .375 & 1,73 & 3.967 .310 & 0,86 \\
\hline Fun & 1.414 .726 & 0,41 & 1.659 .618 & 0,41 & 2.028.312 & 0,47 & 2.220 .024 & 0,48 \\
\hline Carte & 840.231 & 0,24 & 950.039 & 0,23 & 765.296 & 0,18 & 773.044 & 0,17 \\
\hline Gooc & 0.248 .099 & 23,03 & 8.348 .688 & 23,93 & 102.481 .217 & 23,69 & 137.213 .352 & 29,69 \\
\hline $\begin{array}{l}\text { Intangíveis em combinação de } \\
\text { negócios }\end{array}$ & 052 & 273 & 30 & 7,31 & 2 & 561 & 49 & 5,68 \\
\hline Out & 7.427 .581 & 7,88 & 32.771 .800 & 7,98 & 36.275 .587 & 8,39 & 38.797 .542 & 8,40 \\
\hline To & 8.425 .900 & 100 & 0.972 .360 & 100 & 2.526 .522 & 100 & 462.165.896 & 100 \\
\hline Tot: & \multicolumn{2}{|c|}{560.278 .488} & \multicolumn{2}{|c|}{621.407 .996} & \multicolumn{2}{|c|}{ 622.008.064 } & \multicolumn{2}{|c|}{627.137 .402} \\
\hline Ano & \multicolumn{2}{|c|}{2014} & \multicolumn{2}{|l|}{2015} & \multicolumn{2}{|l|}{2016} & \multicolumn{2}{|l|}{2017} \\
\hline Gru & Valor & $(\%)$ & Valor & $(\%)$ & Valor & $(\%)$ & Valor & $(\%)$ \\
\hline Dire & 17.731 .923 & 3,54 & 17.224 .004 & 2,82 & 21.236 .157 & 3,49 & 324 & 3,80 \\
\hline Soft & 13.887 .785 & 2,78 & 15.734 .928 & 2,58 & 16.294 .030 & 2,68 & 15.680 .583 & 2,51 \\
\hline Sist & 6.092 .532 & 1,22 & 6.552 .805 & 1,07 & 6.631 .668 & 1,09 & 6.606 .004 & 1,06 \\
\hline & 333.823 & & 76.385 & & 35.063 & & 41 & 0,91 \\
\hline Cor & 135.734 .357 & 27,13 & 160.529 .410 & 26,30 & .348 .681 & 27,98 & 165.995 .498 & 26,54 \\
\hline Des & 12.689 .242 & 2,54 & 13.374 .980 & 2,19 & 13.434 .035 & 2,20 & 15.378 .610 & 2,46 \\
\hline Em & 60.204 .206 & 12,03 & 90.857 .841 & 14,89 & 80.711 .864 & 13,26 & 61.096 & 13,52 \\
\hline & 11.133 .522 & & 14.100 .795 & 2,31 & 16.445 .217 & 2,70 & 15.390 .098 & 2,46 \\
\hline & 5.953 .893 & & 4.782 .741 & 0,78 & 12.218 .350 & 2,00 & 338 & 1,72 \\
\hline Fun & 2.492 .847 & 0,50 & 2.541 .519 & 0,42 & 2.012.299 & 0,33 & 2.107 .368 & 0,34 \\
\hline Carteira de clientes & 1.219 .014 & 0,24 & 1.410 .850 & 0,23 & 846.587 & 0,14 & 759.329 & 0,12 \\
\hline Goodwill & 151.746 .325 & 30,33 & 195.744 .655 & 32,07 & 180.975 .319 & 29,72 & 185.735 .788 & 29,7 \\
\hline $\begin{array}{l}\text { Intangíveis em combinação de } \\
\text { negócios }\end{array}$ & 28.220 .672 & 64 & 34.720 .385 & 5,69 & 32.367 .924 & 5,32 & 37.944 & 6,07 \\
\hline Outros & .536 & 9,17 & 43.382 .326 & 7,11 & 494.764 & 8,13 & 54.967 .739 & 8,79 \\
\hline Total & 500.328 .677 & 100 & 610.333 .624 & 100 & 608.851 .958 & 100 & 625.327.809 & 100 \\
\hline Total is & 641.394 & & 705.212 & & 669.611 & & 665.12 & \\
\hline
\end{tabular}

Fonte: Dados da pesquisa.

O setor de tecnologia da informação, por exemplo, é um segmento em que se espera que tenha altos valores de desenvolvimento, visto que um dos segmentos é o de programas e serviço, o que, porém, não ocorre. Inclusive, foi um dos menores saldos, fator que pode ser ocasionado pelo não cumprimento dos critérios do CPC 04 R1 (2010), visto que, em 2017, três das sete empresas apresentaram os valores registrados como pesquisa no resultado, somando aproximadamente 452 milhões de reais. Em contrapartida, o setor de telecomunicações representou mais de $72 \%$ de todo o desenvolvimento a partir de 2014, principalmente depois que a Tim Participações S.A. reconheceu os custos de desenvolvimento com a tecnologia $4 \mathrm{G}$.

Comparando 2010 e 2017, percebe-se um aumento significativo. As licenças, por exemplo, quase quadruplicaram de valor (de 2,7 para 107 bilhões de reais) e os direitos e cessões aumentaram $50 \%$ (15,7 para 23,8 bilhões de reais). Por outro lado, a carteira de clientes diminuiu $10 \%$. Esses 
valores sugerem que as entidades aderiram ao CPC 04 R1 (2010), visto que o total de intangível registrado foi aumentando ao longo dos anos.

Nesse lapso temporal, o grupo de natureza de direitos e cessões permaneceu inalterado, contendo cerca de 4 a 5\%, sendo representado em maioria pelo setor de bens industriais, como, por exemplo, a CCR S.A. que, em 2017, possuía 12,8 bilhões de reais de direitos de exploração de rodovias. O mesmo não ocorreu com as concessões e goodwill, conforme visto anteriormente, uma vez que, enquanto o percentual de participação das concessões reduziu, o goodwill aumentou, de maneira que, a partir de 2014, passou a ser a conta com maior representatividade. A redução do valor das concessões pode estar atrelada à amortização, por exemplo, a Petróleo Brasileiro S.A. (Petrobrás), de 80 bilhões de reais em 2010, passou para seis bilhões em 2017.

Em relação ao grupo outros, se percebe que aumentou no decorrer dos anos o valor expresso nos balanços patrimoniais, apesar de sua representatividade ficar em torno dos $8 \%$. Na sua composição, a franquia possuía duas empresas com saldo até 2014. O intangível arrendado foi identificado em uma empresa em 2010 e em quatro em 2017, sendo que apenas duas evidenciaram o que foi arrendado: software e direito de uso de software. Quanto aos pontos comerciais, dobrou o número de empresas, de quatro para oito, de 2010 a 2017, sendo que inicialmente somavam 35.062 milhares de reais, enquanto em 2017 perfaziam 315.017 milhares de reais do total do grupo.

Algumas naturezas se destacam em setores específicos, por exemplo, em serviço e em curso no setor de utilidade pública, marcas e patentes no setor de consumo não cíclico. Dentre as empresas desse setor está a Ambev S.A., cujo intangível representa quase metade do ativo total, sendo as marcas registradas pelo montante de 2,4 bilhões de reais, representando $41,6 \%$ do total das marcas e patentes de 2017.

Para finalizar, pode-se concluir que os intangíveis registrados apresentam itens variados. Cada setor possui um item em particular que mais se destaca, podendo ser explicado pela sua atividade principal. Além disso, ao longo dos anos, pode-se perceber que a natureza dos intangíveis se manteve consolidada, com exceção de poucos itens. Por exemplo, a franquia deixou de ter saldo nas empresas em 2014, e os valores com desenvolvimento, que aumentaram de 50 para 90 empresas de 2010 a 2017.

A Tabela 5 evidencia a estatística descritiva das variáveis. Nota-se que a média do lucro líquido é próxima a zero. Em contrapartida, pode-se dizer que a cada ação, as empresas possuem, em média, 2,89 reais de ativos intangíveis. Pode-se observar também que a média de valor de mercado por ação é superior à média do patrimônio líquido por ação, o que indica que há itens e expectativas futuras que a contabilidade não registra. Ressalta-se que na regressão com dados em painel, o PL e PL-AI negativos foram retirados.

Tabela 5 - Estatística descritiva das variáveis

\begin{tabular}{cccccc}
\hline Variável & Média & Desvio Padrão & Mediana & Mínimo & Máximo \\
\hline VM & 13,4218 & 12,9395 & 9,7124 & 0,00001 & 69,9426 \\
PL & 8,1839 & 8,8668 & 6,5681 & $-27,0671$ & 50,0000 \\
PL-AI & 5,2932 & 8,7208 & 3,3573 & $-27,0736$ & 46,6385 \\
RL & 0,5379 & 1,4676 & 0,4486 & $-5,4785$ & 6,9708 \\
AI & 2,8907 & 4,4417 & 0,6782 & 0,0000002 & 23,9264 \\
\hline
\end{tabular}

Fonte: Dados da pesquisa.

Para verificar a relevância do ativo intangível, inicialmente, verificou-se como o patrimônio líquido e o resultado do exercício influenciam o valor de mercado, conforme a Coluna 1 da Tabela 6. Como se pode observar no Test F, o modelo de Ohlson foi estatisticamente significativo a $1 \%$, induzindo que pelo menos uma das variáveis explicam o valor de mercado. Tanto o patrimônio líquido quanto o resultado líquido foram significativos, conforme o Teste $\mathrm{t}$, ao nível de $1 \%$. Percebese que ambos estão positivamente relacionados ao valor de mercado e podem explicar 38,62\% do valor de mercado das companhias brasileiras analisadas. 
Ao adicionar o ativo intangível no modelo, o poder explicativo aumenta para 39,69\%, ou seja, 1,07 pontos percentuais, conforme a Coluna 2 da Tabela 6 . O incremento do intangível não foi expressivo, porém, foi significativo a $10 \%$. O baixo poder incremental também foi encontrado nas pesquisas de Collins et al. (1997) e Ghahramanizady e Behname (2013), nas quais aumentou 2,7 e 2,97 pontos percentuais, respectivamente. Além disso, o poder explicativo foi similar ao encontrado por Kimouche e Rouabhi (2016).

A variável explicativa foi positivamente relacionada com o valor de mercado, de modo que o intangível pode agregar valor a uma empresa. Com o intuito de verificar o comportamento dos setores em frente aos intangíveis, foram acrescidas variáveis interativas setoriais, os resultados encontramse na Coluna 3 da Tabela 6.

Tabela 6 - Relevância do ativo intangível

\begin{tabular}{|c|c|c|c|c|c|c|c|c|c|}
\hline & \multicolumn{3}{|c|}{ Coluna 1} & \multicolumn{3}{|c|}{ Coluna 2} & \multicolumn{3}{|c|}{ Coluna 3} \\
\hline $\begin{array}{l}\text { Variável } \\
\text { PL }\end{array}$ & $\begin{array}{c}\text { Coef. } \\
0.5547\end{array}$ & $\begin{array}{l}\text { EPad } \\
0,118\end{array}$ & $\begin{array}{c}\text { Estat t } \\
4.69 * * *\end{array}$ & Coef. & EPad & Estat $\mathbf{t}$ & Coef. & EPad & Estat $\mathbf{t}$ \\
\hline $\mathrm{PL}-\mathrm{AI}$ & & & & 0,418 & 0,118 & $3,51 * * *$ & 0,443 & 0,126 & $3,51 * * *$ \\
\hline RL & 2,742 & 0,278 & $9,87 * * *$ & 2,982 & 0,334 & $8,93 * * *$ & 2,905 & 0,334 & $8,69 * * *$ \\
\hline AI & & & & 0,445 & 0,270 & $1,66^{*}$ & & & \\
\hline Bens industriais & & & & & & & 0,108 & 0,402 & 0,27 \\
\hline Telecomunicações & & & & & & & 1,131 & 0,103 & $10,93 * * *$ \\
\hline Consumo cíclico & & & & & & & 0,390 & 0,474 & 0,82 \\
\hline Cons. não cíclico & & & & & & & $-0,661$ & 0,740 & $-0,89$ \\
\hline Materiais básicos & & & & & & & $-0,782$ & 0,585 & $-1,34$ \\
\hline Petróleo, gás, bioc & & & & & & & 1,974 & 1,600 & 1,24 \\
\hline Saúde & & & & & & & 0,335 & 0,450 & 0,75 \\
\hline Utilidade pública & & & & & & & 1,169 & 0,591 & $1,98 * *$ \\
\hline Constante & 7,402 & 1,026 & $7,21 * * *$ & 8,406 & 1,064 & $7,90 * * *$ & 8,448 & 1,035 & $8,16 * * *$ \\
\hline R-sq Within & & 0,2576 & & & 0,263 & & & 0,273 & \\
\hline R-sq Between & & 0,4523 & & & 0,484 & & & 0,35 & \\
\hline R-sq Overall & & 0,3862 & & & 0,396 & & & 0,299 & \\
\hline F-Statistic & & $73,44 * *$ & & & $43,43 *$ & & & $19,66^{*}$ & \\
\hline Teste Reset p-value & & 0,1072 & & & 0,114 & & & 0,174 & \\
\hline $\mathrm{N}$ & & 1256 & & & 1066 & & & 106 & \\
\hline
\end{tabular}

Fonte: Dados da pesquisa. Legenda: ***,**, * significativo a $1 \%, 5 \%$ e $10 \%$, respectivamente.

Os setores de telecomunicações e utilidade pública foram estatisticamente significativos ao nível de $1 \%$. O setor de telecomunicações possui relação com o intangível, visto que possuem pesquisas em desenvolvimento para aprimorar a tecnologia oferecida aos seus usuários, como, por exemplo, a Tim S.A. com a tecnologia $4 \mathrm{G}$ citada anteriormente.

Os achados quanto ao setor de utilidade pública contrariam o estudo de Ferreira et al. (2017), visto que nesta pesquisa foram significativos e positivos, indicando que as concessões acrescentam valor à empresa. Corroboram Cordeiro et al. (2017), indicando que, apesar de possuir a contabilidade regulatória, os valores presentes na contabilidade societária quanto às concessões são relevantes para o investidor.

Os setores de bens industriais, consumo cíclico, consumo não cíclico e materiais básicos não foram significativos, o que pode ser decorrente dos intangíveis não estarem ligados à atividade principal, com exceção das marcas (consumo não cíclico).

O setor de saúde também não foi significativo, mesmo possuindo fórmulas, patentes e desenvolvimento de novos produtos como atividade principal. Tal resultado pode ser explicado pelo receio do investidor no reconhecimento desses itens, corroborando os rigorosos critérios para reconhecimento de intangíveis gerados internamente estabelecidos no CPC 04 R1 (2010). Assim, como o setor de petróleo, gás e biocombustível, apesar de ter intangíveis relacionados à atividade principal da empresa, como concessões de exploração, não foi significativo. 
$\mathrm{O}$ fato de que setores que vinculam a atividade principal ao intangível terem sido significativos ressalta a relevância que esse tipo de ativo pode ter para essas empresas. Com o intuito de verificar como reage o valor de mercado quando segregado o intangível de acordo com a natureza, foi elaborada a Equação 4.

Os resultados encontram-se na Tabela 7. O modelo proposto pelos grupos de natureza possui um poder explicativo de $42,56 \%$, maior se comparado tanto ao modelo base como ao do intangível geral, induzindo que o mercado considera relevante o tipo de intangível que a empresa possui, contrariando os achados de Carlos Filho et al. (2013). Além disso, dos 14 grupos, oito não foram estatisticamente significativos: direitos e cessões, sistemas e implantações, concessões, em serviço, licença, goodwill, intangíveis reconhecidos em combinação de negócios e outros. Uma possível explicação para os sistemas e implantações e outros intangíveis seria que esses itens são utilizados para as atividades do dia a dia, de modo que não influencia a empresa possuir ou não esses intangíveis, não sendo relevantes para compor o valor de mercado. Quanto às concessões, podem ser explicadas pelo fato de serem encontradas principalmente no setor de petróleo, gás e biocombustível, que também não apontou ter intangíveis significativos, indicando sua insignificância para o mercado como um todo.

Tabela 7 - Relevância da natureza do ativo intangível

\begin{tabular}{|c|c|c|c|c|}
\hline \multicolumn{5}{|c|}{ Painel A } \\
\hline Variável & Coeficiente & Erro Padrão & Estatística $\mathbf{t}$ & P-Value \\
\hline $\mathrm{PL}-\mathrm{AI}$ & 0,5250 & 0,1490 & $3,52 * * *$ & 0,001 \\
\hline RL & 3,0802 & 0,3555 & $8,66 * * *$ & 0,000 \\
\hline Direitos e cessões (DIRT) & 0,8426 & 0,8094 & 1,04 & 0,299 \\
\hline Software (SOFT) & $-4,4935$ & 2,1821 & $-2,06 * *$ & 0,041 \\
\hline Sistemas e implantações (SIST) & 2,9157 & 2,2414 & 1,30 & 0,195 \\
\hline Marcas e patentes (MEP) & 2,1855 & 1,1154 & $1,96 * *$ & 0,052 \\
\hline Concessões (CONC) & 0,4241 & 0,3611 & 1,17 & 0,245 \\
\hline Desenvolvimento (DESEN) & 0,8707 & 0,4694 & $1,85^{*}$ & 0,065 \\
\hline Em serviço (SERV) & 0,4177 & 0,5373 & 0,78 & 0,438 \\
\hline Em curso (CURS) & 7,0453 & 1,0205 & $6,90 * * *$ & 0,000 \\
\hline Licença (LIC) & 0,6122 & 8,5078 & 0,07 & 0,943 \\
\hline Fundo de comércio (FUND) & 15,3157 & 4,5463 & $3,37 * * *$ & 0,001 \\
\hline Carteira de clientes (CART) & 18,0350 & 6,1587 & $2,93 * * *$ & 0,004 \\
\hline Goodwill (GOOD) & 0,3234 & 0,4534 & 0,71 & 0,477 \\
\hline Intangível em comb. de negócio & 0,1430 & 0,9368 & 0,15 & 0,879 \\
\hline Outros (OUT) & 1,1986 & 1,2863 & 0,93 & 0,353 \\
\hline Constante & 7,4825 & 1,1274 & $6,64 * * *$ & 0,000 \\
\hline \multicolumn{5}{|c|}{ Painel B } \\
\hline R-sq Within & \multicolumn{2}{|c|}{ F-Statistic } & \multicolumn{2}{|l|}{$14,65 * * *$} \\
\hline R-sq Between & \multicolumn{2}{|c|}{ Teste Reset (p-value) } & \multicolumn{2}{|l|}{0,0140} \\
\hline R-sq Overall & \multicolumn{2}{|c|}{$\mathrm{N}$} & \multicolumn{2}{|l|}{946} \\
\hline
\end{tabular}

Fonte: Dados da pesquisa. Legenda: ***, **, * significativo a $1 \%, 5 \%$ e $10 \%$, respectivamente.

Os intangíveis em serviço não foram relevantes, diferente dos intangíveis em curso. Isso pode ser devido ao fato de os intangíveis em serviço serem consumidos no momento, enquanto os em curso refletirão os benefícios futuros advindos dos contratos. A indicação de benefícios futuros pode ser observada também na variável desenvolvimento, na qual valores gastos com o desenvolvimento e aprimoramento dos produtos cumpriram os critérios de reconhecimento do CPC 04 R1 (2010) e puderam ser ativados. O mercado acionário se mostra interessado nesses valores, visto que há probabilidade desses ativos acrescerem o valor de mercado da companhia.

Quanto aos intangíveis identificados e reconhecidos em combinações de negócios, corrobora os achados de Souza e Borba (2017), de que esses intangíveis não são relevantes para o mercado acionário, assim como o goodwill, corroborando os resultados de Souza e Borba (2017) e Herculano e Piccoli (2016). 
Os demais se mostraram significativos a $1 \%, 5 \%$ e $10 \%$ para o valor de mercado, além disso, com exceção do software, todas as variáveis estão positivamente relacionadas com o valor de mercado. Dentre eles, o fundo de comércio e a carteira de clientes obtiveram os maiores coeficientes. Uma justificativa para o fundo de comércio seria que as empresas acabam considerando relevantes os pontos comerciais, visto que aquelas que especificaram o que seria esse fundo de comércio fizeram referência aos pontos comerciais. Quanto à carteira de clientes, uma explicação seria que esta apresenta uma consolidação da empresa frente ao setor atuante. Com relação às marcas e patentes, corroboram os achados de Kallupar e Kwan (2004), de que as marcas, mesmo quando há erros na mensuração, continuam sendo relevantes para o mercado acionário, por dizerem respeito à reputação da empresa, além de agregarem valor ao produto e serviço oferecido.

Com base no poder incremental encontrado no intangível e a relevância observada em seis grupos de natureza, sustentam-se as hipóteses 1 e 2, não rejeitando-as, de modo que o ativo intangível está positivamente relacionado com o valor de mercado das empresas, assim como com a sua natureza. Corroborando os achados de Ji e Lu (2014) no contexto australiano, e os estudos de Carlos Filho et al. (2013) e Silva et al. (2017) no contexto brasileiro, infere-se que o ativo intangível, independentemente de sua natureza, é relevante para o mercado acionário. O estudo também corrobora os achados de Pacheco et al. (2018), induzindo que tanto o valor dos intangíveis como seu nível de evidenciação são considerados no momento de formular as premissas para a tomada de decisão de onde investir e, possivelmente, elevar o valor de mercado.

\section{CONSIDERAÇÕES FINAIS}

Com a adesão das normas contábeis internacionais nas companhias de capital aberto brasileiras e a emissão do CPC 04 R1 (2010), o modo como os intangíveis eram contabilizados foi modificado. Itens que anteriormente poderiam ser contabilizados no intangível passaram a figurar como despesas. Em contrapartida, itens que eram amortizados passaram a ter vida útil indefinida. $\mathrm{O}$ intangível passou a constar como uma possível diferença entre o valor de mercado e o valor contábil. Desse modo, o objetivo da pesquisa foi verificar a relevância da natureza dos ativos intangíveis das companhias abertas brasileiras para o mercado acionário.

Sobre o reconhecimento dos intangíveis, ao longo dos oito anos analisados, observou-se um crescimento, também identificado por Collins et al. (1997) na década de 50 a 90, de modo que continuam a crescer, contribuindo para a geração de valor de mercado da empresa, visto suas particularidades nas atividades empresariais.

No que tange à relevância do intangível para o valor de mercado, esta foi estatisticamente comprovada. Além disso, certas naturezas de intangível demonstraram-se mais relevantes do que outras. Por exemplo, as carteiras de clientes com o coeficiente positivo e significativo de 18,03, enquanto as licenças não foram significativas.

Os resultados demonstram que tanto o desenvolvimento de novos produtos, como o intangível em curso são relevantes para o mercado acionário. Isso pode indicar que, além de perceber os benefícios futuros envolvidos com esses ativos, o mercado acredita que eles contribuem para seu lucro residual. Este considera os lucros futuros, os quais podem ser derivados de gastos com pesquisa e demais atividades da empresa, que possuem relação com os intangíveis e podem agregar à criação de valor da empresa no futuro.

Com isso, entende-se que desde a adesão das normas contábeis internacionais, em 2010, juntamente com o esforço das empresas em registrar e evidenciar seus ativos intangíveis, bem como possíveis gastos com pesquisa, há um auxílio no processo de criação de valor da empresa, e isso é refletido no valor de mercado.

Ademais, foi possível identificar que a empresa, cuja atividade principal envolva algum intangível, possui valores superiores àquelas cuja atividade não necessite desse tipo de ativo. Por exemplo, o desenvolvimento das telecomunicações com o setor de consumo não cíclico. De modo 
geral, o ativo intangível mostrou-se significativo para o valor de mercado, configurou-se como relevante, independentemente do tipo de intangível que a empresa possui.

A pesquisa limita-se às empresas não financeiras brasileiras, visto que outros países podem possuir percepções diferentes sobre as variáveis analisadas. Limita-se ao período analisado, não podendo ser considerado o período anterior à adesão das normas contábeis internacionais, nem período anterior ao pronunciamento do CPC 04 R1 (2010).

Para futuras pesquisas, sugere-se analisar as empresas financeiras, para verificar se os intangíveis possuem a mesma relevância e que tipos de intangíveis registram. Sugere-se, também, explorar outras abordagens metodológicas, para verificar a relevância do intangível e explorar os setores trimestralmente quanto à pesquisa e desenvolvimento, a fim de verificar se modifica $o$ entendimento do setor.

\section{REFERÊNCIAS}

Aboody, D., \& Lev, B. (1998). The value relevance of intangibles: The case of software capitalization. Journal of Accounting Research, 36, 161-191.

Abubakar, S., \& Abubakar, M. (2015). Intangible assets and value relevance of accounting information of listed High-Tech firms in Nigeria. Research Journal of Finance and Accounting, 6(11), 60-79.

Badenhausen, K. (2019). As 100 marcas mais valiosas do mundo em 2019. Forbes, São Paulo, mai. 2019. Disponível em: https://forbes.com.br/listas/2019/05/as-100-marcas-mais-valiosas-do-mundo-em-2019/

Ball, R., \& Brown, P. (1968). An empirical evaluation of accounting income numbers. Journal of Accounting Research, 6(2), 159-178.

Barth, M. E., Beaver, W. H., \& Landsman, W. R. (2001). The relevance of the value relevance literature for financial accounting standard setting: another view. Journal of Accounting and Economics, 31(1-3), 77-104.

Beaver, W. H. (1968). The information content of annual earnings announcements. Journal of Accounting Research, 6, 67-92.

Benston, G. J. (1967). Published corporate accounting data and stock prices. Journal of Accounting Research, 5, 22-54.

Bizotto, B. L. S., Rali, G., Ribeiro, B., Stancki, G.L. (2014). Fundo de comercio: O Intangível de maior relevância para as empresas. In: XIV Mostra de Iniciação Científica, Pós-graduação, Pesquisa e Extensão.

Brasília (Distrito Federal). Deliberação CVM No 488, de 03 de Outubro de 2005. [Aprova o pronunciamento do IBRACON NPC n 27 sobre Demonstrações Contábeis - Apresentação e Divulgações]. Diário Oficial, 03. Out. 2005.

Carlos Filho, F. D. A., Silva Filho, L. L., Lagioia, U. C. T., Silva, I. É. M., \& Araújo, J. G. (2013). A adoção das normas internacionais de contabilidade ocasionou um maior reconhecimento dos ativos intangíveis no Brasil? Revista Catarinense da Ciência Contábil, 12(37), 51-63.

Cassel, C. M., Hackl, P., \& Westlund, A. H. (2000). On measurement of intangible assets: A study of robustness of partial least squares. Total Quality Management, 11(7), 897-907.

Castro, W. B. (2015). O impacto das restrições para registro dos ativos intangíveis na diferença entre o valor de mercado e o valor contábil. Revista Brasileira de Contabilidade, 215, 69-81.

Chauvin, K. W., \& Hirschey, M. (1994). Goodwill, profitability, and the market value of the firm. Journal of Accounting and Public Policy, 13(2), 159-180.

Collins, D. W., Maydew, E. L., \& Weiss, I. S. (1997). Changes in the value-relevance of earnings and book values over the past forty years. Journal of Accounting and Economics, 24(1), 39-67.

Comitê de Pronunciamentos Contábeis. Pronunciamento Técnico CPC 04 R1, de 05 de novembro de 2010. Ativo intangível. Disponível em: http://www.cpc.org.br.

Cordeiro, J. F., Carmo, C. H. S., \& Ribeiro, A. M. (2017). Contabilidade societária ou contabilidade regulatória? Value relevance das informações contábeis do setor brasileiro de energia elétrica. In USP International Conference in Accounting (17).

Eloy, J. C. C., \& de Souza, M. M. (2018). Reconhecimento dos ativos intangíveis nas combinações de negócios: Uma análise nas características das companhias de capital aberto brasileiras no período entre 2012 e 2014. Revista de Contabilidade da UFBA, 12(1), 116-136. 
Ernst \& Young. (2013). Análises sobre o IFRS no Brasil. FIPECAFI, 452p. Recuperado de: https://edisciplinas.usp.br/pluginfile.php/223909/mod_resource/content/1/Pesquisa_EY_Fipecafi_201 3_Web.pdf

Fama, E. F. (1970). Efficient capital markets: A review of theory and empirical work. The Journal of Finance, 25(2), 383-417.

Ferreira, G. D., Carmo, C. H. S., Moura, P. J. P., \& Ribeiro, A. M. (2017). Value relevance de ativos intangíveis: Uma análise nas empresas do setor de energia elétrica da bolsa brasileira. In USP International Conference In Accounting (17).

García-Ayuso, M. (2003). Factors explaining the inefficient valuation of intangibles. Accounting, Auditing \& Accountability Journal, 16(1), 57-69.

Ghahramanizady, M., \& Behname, M. (2013). Intangible assets value relevance; metals industry of Tehran stock exchange case study. Technical Journal of Engineering and Applied Sciences, 3(21), 27592765.

Hadi, A. S. (1992). Identifying multiple outliers in multivariate data. Journal of the Royal Statistical Society: Series B (Methodological), 54(3), 761-771.

Herculano, H. A., \& Piccoli, M. R. (2016). Reconhecimento de ativos intangíveis: Uma análise sobre o value relevance no Brasil. Revista Mineira de Contabilidade, 17(1), 62-72.

Ji, X. D., \& Lu, W. (2014). The value relevance and reliability of intangible assets: evidence from Australia before and after adopting IFRS. Asian Review of Accounting, 22(3), 182-216.

Kallapur, S., \& Kwan, S. Y. (2004). The value relevance and reliability of brand assets recognized by UK firms. The Accounting Review, 79(1), 151-172.

Kayo, E. K., Kimura, H., Martin, D. M. L., \& Nakamura, W. T. (2006). Ativos intangíveis, ciclo de vida e criação de valor. Revista de Administração Contemporânea, 10(3), 73-90.

Kimouche, B., \& Rouabhi, A. (2016). The impact of intangibles on the value relevance of accounting information: Evidence from French companies. Intangible Capital, 12(2), 506-529.

Lev, B. (2003). Remarks on the measurement, valuation, and reporting of intangible assets. FRBNY Economic Policy Review, 9,(3), 17-22.

Lev, B., \& Sougiannis, T. (1996). The capitalization, amortization, and value-relevance of R\&D. Journal of Accounting and Economics, 21(1), 107-138.

Mansuri, B. B. (2016). Emerging issues in accounting for intangible assets. International Journal of Economics, Commerce and Management, 4(1), 608-614.

Mantovani, E. F. V., \& Almeida Santos, F. (2014). A contabilização do ativo intangível nas 522 empresas listadas na BM\&FBOVESPA. RAI Revista de Administração e Inovação, 11(4), 310-328.

Martins, E., Almeida, D. L. D., Martins, E. A., \& Costa, P. D. S. (2010). Goodwill: Uma análise dos conceitos utilizados em trabalhos científicos. Revista Contabilidade \& Finanças, 21(52), 1-25.

Miguel, C. (2011). Como empreendedores podem valorizar bens intangíveis de uma empresa? Exame, São Paulo. Recuperado de: https://exame.com/pme/patrimonio-intocavel/

Ohlson, J. A. (1995). Earnings, book values, and dividends in equity valuation. Contemporary Accounting Research, 11(2), 661-687.

Oliveira, L., Rodrigues, L. L., \& Craig, R. (2010). Intangible assets and value relevance: Evidence from the Portuguese stock exchange. The British Accounting Review, 42(4), 241-252.

Organização das Nações Unidas (2017). Um terço do valor de produtos indústrias são de "capital intangível". Recuperado de: https://news.un.org/pt/story/2017/11/1600762-um-terco-do-valor-de-produtosindustrias-sao-de-capital-intangivel\#.WhXf9VWnFhF.

Pacheco, J., Rover, S., \& Vicente, E. F. R. (2018). Value relevance do nível de evidenciação do ativo intangível nas companhias de capital aberto brasileiras. Revista Contemporânea de Contabilidade, 15(37), 178-199.

Patrocínio, M. R., Kayo, E. K., \& Kimura, H. (2007). Aquisição de empresas, intangibilidade e criação de valor: um estudo de evento. Revista de Administração, 42(2), 205-215.

Ramsey, J. B. (1969). Tests for specification errors in classical linear least-squares regression analysis. Journal of the Royal Statistical Society: Series B (Methodological), 31(2), 350-371.

Ritta, C. O., Ensslin, S. R., \& Ronchi, S. H. (2010). A evidenciação dos ativos intangíveis nas empresas brasileiras: Empresas que apresentaram informações financeiras à bolsa de valores de São Paulo e Nova York em 2006 e 2007. Revista Eletrônica de Ciência Administrativa, 9(1), 62-75. 
Santos, G. S. P. (2018). Organizações exponenciais: Uma análise do desenvolvimento de startups na incubadora MIDI tecnológico. 2018. 236f. Tese (Doutorado em Engenharia e Gestão do Conhecimento) - Curso de Pós-Graduação em Engenharia e Gestão do Conhecimento, Universidade Federal de Santa Catarina, Florianópolis.

Santos, N. J. (2018). Avaliação de empresas: Aspectos objetivos na verificação de valor econômico de ativos intangíveis. Revista Catarinense da Ciência Contábil, 17(50), 23-36.

Shah, S. Z. A., Liang, S., \& Akbar, S. (2013). International Financial Reporting Standards and the value relevance of R\&D expenditures: Pre and post IFRS analysis. International Review of Financial Analysis, 30, 158-169.

Silva, A., Souza, T. R., \& Klann, R. C. (2017). A influência dos ativos intangíveis na relevância da informação contábil. Revista Contemporânea de Contabilidade, 14(31), 26-45.

Sorin-George, T., \& Catalin, G. (2017). The world's most innovative companies in the period 2015-2016. Ovidius University Annals, Economic Sciences Series, 17(1), 69-73.

Souza, M. M. D., \& Borba, J. A. (2017). Value relevance do nível de disclosure das combinações de negócios e do goodwill reconhecido nas companhias de capital aberto brasileiras. Revista Contabilidade \& Finanças, 28(73), 77-92.

Vasconcelos, T., Forte, D., \& Basso, L. F. (2019). The impact of intangibles of German, English and Portuguese companies: From 1999 to 2016. RAM Revista de Administração Mackenzie, 20(4), 1-38.

Kloeppel, N., Zittei, M. V. M., \& Klann, R. C. (2013). Ativos intangíveis: reconhecimento em empresas de utilidade pública listadas na BM\&FBovespa. Revista de Estudos Contábeis, 4(7), 98-115. 